\title{
Surface Acoustic Wave Sensors for Ammonia Detection at Room Temperature Based on $\mathrm{SnO}_{2} / \mathrm{Co}_{3} \mathrm{O}_{4}$ Bilayers
}

\author{
Izabela Constantinoiu (D), Dana Miu (D), and Cristian Viespe (D) \\ Laser Department, National Institute for Lasers, Plasma and Radiation Physics, Magurele, RO-077125 Bucharest, Romania \\ Correspondence should be addressed to Cristian Viespe; cristian.viespe@inflpr.ro
}

Received 14 December 2018; Revised 18 February 2019; Accepted 4 March 2019; Published 19 May 2019

Academic Editor: Ylias Sabri

Copyright (C) 2019 Izabela Constantinoiu et al. This is an open access article distributed under the Creative Commons Attribution License, which permits unrestricted use, distribution, and reproduction in any medium, provided the original work is properly cited.

\begin{abstract}
The selectivity of a SAW (surface acoustic wave) sensor, with a $\mathrm{Co}_{3} \mathrm{O}_{4}$ sensitive thin film for $\mathrm{NH}_{3}$ (ammonia) and the influence of $\mathrm{SnO}_{2}$ on its sensitivity, was studied. Thin films were deposited by pulsed laser deposition (PLD) on quartz SAW sensor substrates. Two sensors with different types of sensitive films were developed: $\mathrm{C}_{3} \mathrm{O}_{4}$ thin film sensor (S1) and a $\mathrm{SnO}_{2} / \mathrm{Co}_{3} \mathrm{O}_{4}$ thin film sensor (S2). The sensitive films were deposited in conditions which ensured a porous structure. The sensors were tested in the presence of three gases: $\mathrm{NH}_{3}$, methanol, and toluene. The selectivity of $\mathrm{Co}_{3} \mathrm{O}_{4}$ for $\mathrm{NH}_{3}$ was determined from the difference in the frequency shifts of the sensor for $\mathrm{NH}_{3}$ and for VOCs (volatile organic compounds). The positive influence of $\mathrm{SnO}_{2}$ on the sensitivity of sensor S2 was observed from the lower limit of detection (LOD) of this sensor and from the differences in frequency shifts between sensor S1 and sensor S2.
\end{abstract}

\section{Introduction}

Ammonia $\left(\mathrm{NH}_{3}\right)$ is a substance of interest in various domains (agriculture, cleaning products, refrigerants, etc.). It is being actively studied for a chemical energy storage, which is crucial for compensating the intermittent character of renewable energy [1]. However, the use of $\mathrm{NH}_{3}$ requires strict safety precautions, due to the fact that it can lead to severe health problems, and is flammable in air at $50^{\circ} \mathrm{C}$ at concentrations over $160000 \mathrm{ppm}$ [2]. Since the maximum permissible exposure limit is $25 \mathrm{ppm}$, it is important to develop sensors capable of detecting the presence of $\mathrm{NH}_{3}$ at such levels.

Volatile organic compounds (VOCs) also have a detrimental effect on the environment and on health [3]. They are released into the atmosphere by combustion of fuels such as gas, wood, coal, or natural gas but can also derive from paints, cigarettes, and other consumer products [4].

Resistance-based sensors, as well as optical devices or MOS-field effect transistors, have been used for detecting such hazardous substances $[5,6]$. However, they have inherent disadvantages such as high working temperature, poor selectivity, or relatively long recovery times. For instance, resistance-based sensors used for $\mathrm{NH}_{3}$ detection give poor results at room temperature (RT) and therefore require operation at relatively high temperatures (over $140^{\circ} \mathrm{C}$ ) [7].

SAW (surface acoustic wave) sensors present a series of important advantages such as high sensitivity, fast response, reliability, low cost, ease of fabrication, and possibility of wireless operation $[8,9]$. The sensing mechanism for SAW sensors is based on the fact that the propagation of the acoustic wave at the surface of the sensor is affected by perturbations generated by mechanical and/or electrical effects in the presence of the analyte. Various materials are used for the sensing film in SAW sensors, such as polymers [10] p-type or n-type semiconducting oxides [11, 12]. Generally, for the SAW detection of VOCs, sensitive films are made of oxide or composite materials (polymers, nanoparticles) [13].

$\mathrm{Co}_{3} \mathrm{O}_{4}$ is a p-type semiconductor which has been used for $\mathrm{NH}_{3}$ detection in various types of sensors [14], including SAWs [15]. However, $\mathrm{Co}_{3} \mathrm{O}_{4}$ alone does not give satisfactory response to $\mathrm{NH}_{3}$, especially at RT [15]. It is known that multilayer SAW sensing layers can improve the sensing 
properties of SAW sensors compared to single layers, by ensuring a larger acoustoelectrical response to the gas, in addition to the mass loading effect $[16,17]$. This leads to an increase of sensitivity and a decrease of the sensing limit, even at RT.

$\mathrm{SnO}_{2}$ is an n-type semiconductor and one of the oxides most widely used in sensors. It is often used in the detection of reducing gases due to the active oxygen species present on its surface. The interaction between reducing gas molecules and oxygen species favors adsorption at the film level and leads to a change in conductivity [18]. One of the disadvantages of $\mathrm{SnO}_{2}$ in gas detection is the lack of selectivity [19], which can be improved, depending on the gas which needs to be identified, by combining it with another material that offers selectivity for the specific analyte. We have therefore considered a bilayer $\mathrm{Co}_{3} \mathrm{O}_{4} / \mathrm{SnO}_{2}$ sensing film in order to improve the response of the SAW sensor it is incorporated in, to $\mathrm{NH}_{3}$ and VOCs. This also allows us to study the selectivity of the sensor, as was done before to determine the selectivity of other sensing layers $(\mathrm{ZnO})$ to $\mathrm{NH}_{3}$ [9].

The sensing bilayer was deposited using pulsed laser deposition (PLD). The advantage of this method is that it is more straightforward than chemical methods requiring many intermediate steps $[20,21]$. PLD also has the great advantage of allowing a simple control of layer porosity, which is known to be important for improved gas sensor properties [22]. Nanoporous films facilitate rapid in/out diffusion of gas species in/out of the sensor (which shortens the sensor response and recovery times). Such films also lead to a larger film surface area, which considerably increases the sensor sensitivity. It is much more difficult to obtain such nanoporous films using chemical methods [23] than by PLD.

In the present paper, we present the sensing properties of SAW sensors based on $\mathrm{SnO}_{2} / \mathrm{Co}_{3} \mathrm{O}_{4}$ bilayers, as well as for a single $\mathrm{Co}_{3} \mathrm{O}_{4}$ layer, obtained by PLD. The sensitivity, response, and recovery times of the sensors in the case of $\mathrm{NH}_{3}$ detection and for VOCs (methanol and toluene) were determined. We have analyzed the sensitivity of $\mathrm{Co}_{3} \mathrm{O}_{4}$ for $\mathrm{NH}_{3}$, the influence of $\mathrm{SnO}_{2}$ thin film on sensor sensitivity, and its ability to detect $\mathrm{NH}_{3}$ at RT.

\section{Materials and Methods}

The SAW sensors are based on a quartz substrate (ST cut, X propagation, $38 \mathrm{~mm}$ long, $10 \mathrm{~mm}$ wide, $0.5 \mathrm{~mm}$ thick), cut in a parallelogram geometry to reduce the effects of the unwanted SAW reflections. The SAW sensor is a "delayline" type with an oscillating frequency of $69 \mathrm{MHz}$ [24]. The $150 \mathrm{~nm}$ thick gold interdigital transducers (IDT) were deposited using standard photolithographic techniques onto $10 \mathrm{~nm}$ thick chromium layers (which ensure gold adhesion to the quartz substrate). The IDT were made in a "doublecomb" configuration, consisting in 50 straight finger pairs with a $2500 \mu \mathrm{m}$ acoustic aperture and a $45.2 \mu \mathrm{m}$ wavelength.

The bilayers were deposited by PLD using an Nd-YAG laser (EKSPLA NL301HT) having pulse durations of about $5 \mathrm{~ns}$, at a repetition rate of $10 \mathrm{~Hz}$. A UV wavelength of $355 \mathrm{~nm}$ was used with an energy per pulse of about $40 \mathrm{~mJ}$.

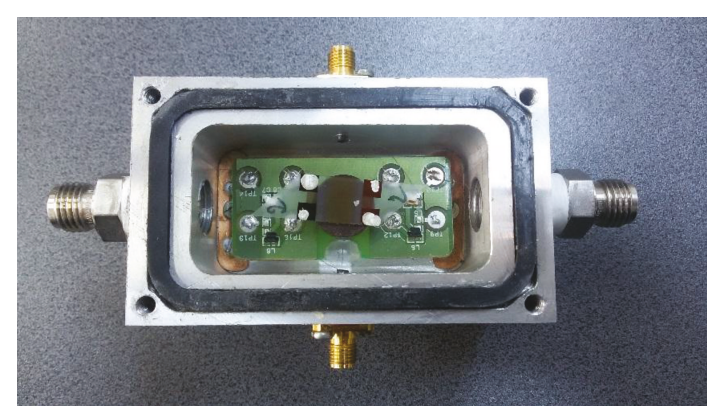

FIgURE 1: SAW S2 sensor in a test chamber.

An energy density of about $25 \mathrm{~J} / \mathrm{cm}^{2}$ was obtained by focusing the laser beam onto the targets.

$\mathrm{SnO}_{2}$ and $\mathrm{Co}$ targets were placed in a vacuum chamber on computer-controlled $x-y$ tables which allow successive ablation of multiple targets as well as target movement during deposition in order to avoid target erosion. The vacuum chamber is equipped with a gas pressure and flow control system, which consists in a combination of mass flow controllers on the gas bottles and a throttle valve controlled by a pressure controller on a rotary vane vacuum pump. The ST-X cut quartz substrates are placed $40 \mathrm{~mm}$ from the target. Both $\mathrm{Co}_{3} \mathrm{O}_{4}$ layers and $\mathrm{Co}_{3} \mathrm{O}_{4} / \mathrm{SnO}_{2}$ bilayers were deposited. The $\mathrm{Co}_{3} \mathrm{O}_{4}$ layers were deposited using 76000 pulses, leading to a thickness of about $250-300 \mathrm{~nm}$, while the $\mathrm{SnO}_{2}$ layer was deposited with 7200 pulses, leading to a thickness of 20$30 \mathrm{~nm}$. All depositions were made at RT. An oxygen deposition pressure of 300 mTorr was used for both targets in order to ensure porosity of the thin film, as well as proper film stoichiometry.

The SAW sensors based on the $\mathrm{Co}_{3} \mathrm{O}_{4}$ layer ( $\left.\mathrm{S} 1\right)$ and the $\mathrm{SnO}_{2} / \mathrm{Co}_{3} \mathrm{O}_{4}$ bilayer (S2) were tested towards $\mathrm{NH}_{3}$ and VOCs (methanol and toluene). The sensor operating scheme is presented in our previous works [11]. Figure 1 depicts the S2 SAW sensor in the test chamber. The frequency shift was measured with a CNT-91 Pendulum frequency counter connected to a computer with Time View 3 software. The circuit signal loss was compensated with a DHPVA-100 FEMTO amplifier $(10-60 \mathrm{~dB}, 100 \mathrm{MHz})$. The response of the sensors to different concentrations of $\mathrm{NH}_{3}$ and VOCs (methanol and toluene) was determined. Different quantities of analytes were injected in the mixer chamber. The flow rate of the VOC/air mixture was maintained constant at $150 \mathrm{~cm}^{3} / \mathrm{s}$ with a diaphragm pump (Pfeiffer MVP 035-2) for all the measurements. The temperature was maintained constant during the measurements, as well.

\section{Results and Discussions}

In X-ray diffraction, no peaks other than those of the substrate were visible, indicating that the sensitive layers are amorphous.

The film morphology was analyzed using scanning electron microscopy (SEM, Thermo Scientific Apreo S). SEM images indicate nanoporosity of the layers (Figures 2(a) and 2(b)), especially $\mathrm{SnO}_{2}$. This nanoporosity favors gas diffusion into the layers. The thicknesses of the thin films are about 


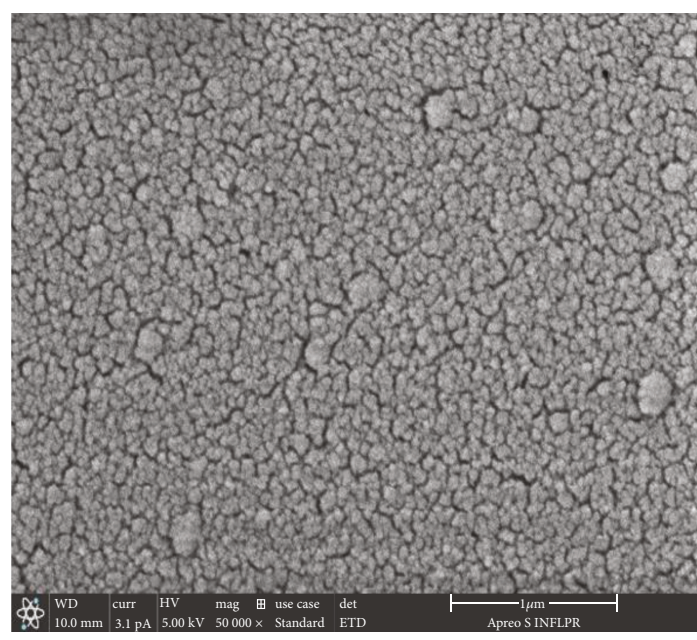

(a)

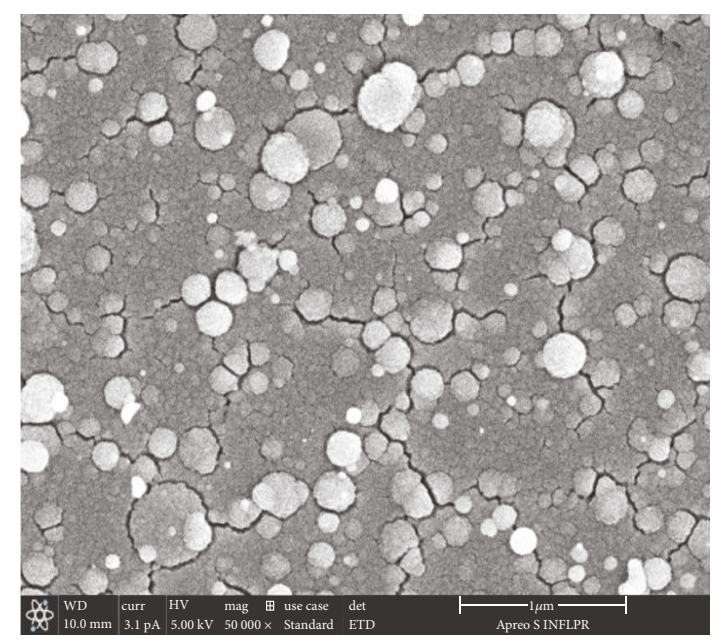

(b)

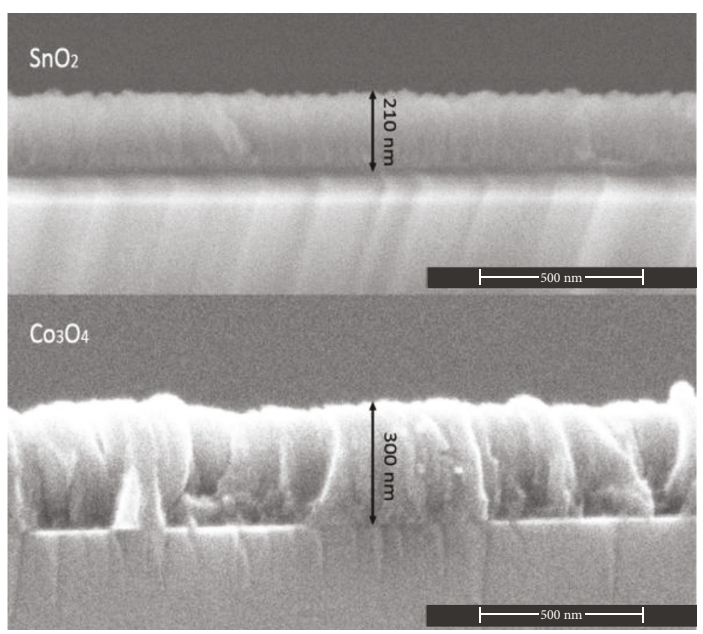

(c)

FIgURE 2: SEM images of (a) $\mathrm{SnO}_{2}$ layer, (b) $\mathrm{Co}_{3} \mathrm{O}_{4}$ layer, and (c) $\mathrm{SnO}_{2}$ and $\mathrm{Co}_{3} \mathrm{O}_{4}$ layer cross section.

TABLE 1: Sensitivity and limit of detection.

\begin{tabular}{lcccccc}
\hline \multirow{2}{*}{ SAW sensor } & $\mathrm{NH}_{3}$ & & Methanol & Toluene & Lon \\
& Sensitivity $\Delta f / c(\mathrm{~Hz} / \mathrm{ppm})$ & LOD $(\mathrm{ppm})$ & Sensitivity $\Delta f / c(\mathrm{~Hz} / \mathrm{ppm})$ & LOD $(\mathrm{ppm})$ & Sensitivity $\Delta f / c(\mathrm{~Hz} / \mathrm{ppm})$ & LOD $(\mathrm{ppm})$ \\
\hline S1 & 2.00 & 15 & 0.83 & 36 & 0.50 & 60 \\
S2 & 3.33 & 9 & 1.33 & 23 & 0.60 & 50 \\
\hline
\end{tabular}

$\Delta f$ : frequency change and $c$ : analyte gas concentration for the two sensitive films.

$210 \mathrm{~nm}$ for $\mathrm{SnO}_{2}$ and $300 \mathrm{~nm}$ for $\mathrm{Co}_{3} \mathrm{O}_{4}$ as it can be seen in Figure 2(c).

The frequency shifts of sensors S1 and S2 in the presence of $\mathrm{NH}_{3}$, methanol, and toluene were measured. Figure 2 presents the dependence of these frequency shifts on the concentration of the analyte introduced in the test chamber. A remarkable difference between the frequency shifts in the presence of $\mathrm{NH}_{3}$ for the two sensors is evident. Sensor S2 presents a larger frequency shift than $\mathrm{S} 1$ at the same analyte concentration. In the case of methanol and toluene, although there are differences in the frequency shifts of S1 and S2 at the same analyte concentrations, these are noticeably lower than that for $\mathrm{NH}_{3}$. Repeating 10 measurements of the frequency deviation for each of the 2 sensor films yielded errors below $\pm 3.5 \%$.

Table 1 presents the sensitivity and limit of detection for the two sensitive films. The sensitivity, defined as the frequency shift in $\mathrm{Hz}$ per unit analyte concentration in ppm, was determined from the data shown in Figure 3. The limit of detection (LOD) is defined as three times the noise level per sensitivity. The noise level was around $10 \mathrm{~Hz}$ for all sensors and was determined by measuring the resonance frequency for $10 \mathrm{~min}$ as a maximum frequency deviation from the trend line. The results in the table indicate that there is a sensitivity difference between the two sensors for the same analyte. This is true for all three gas types studied, and S2 


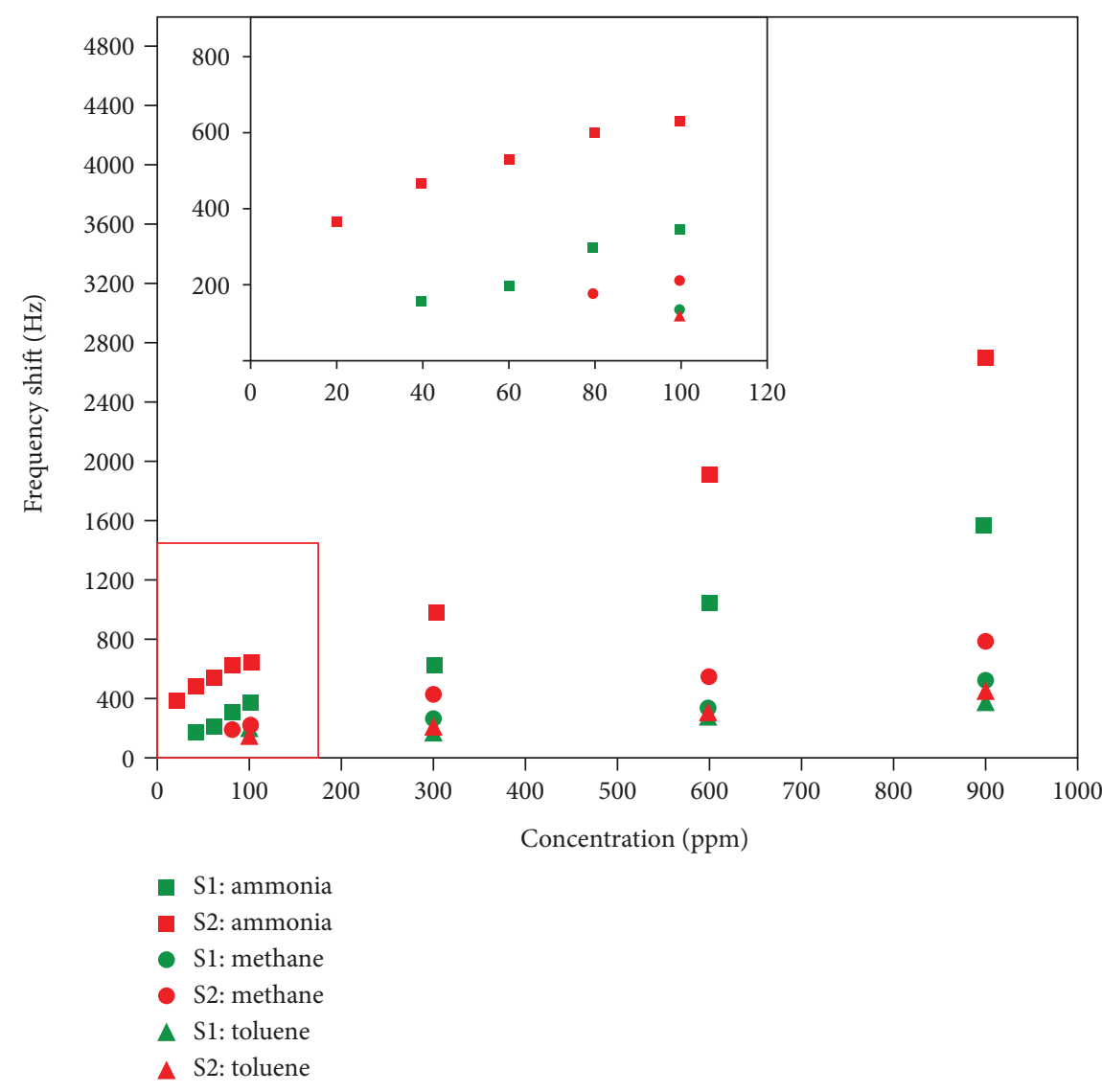

FIgURE 3: Response of sensor S2 as a function of $\mathrm{NH}_{3}$, methanol, and toluene concentration.

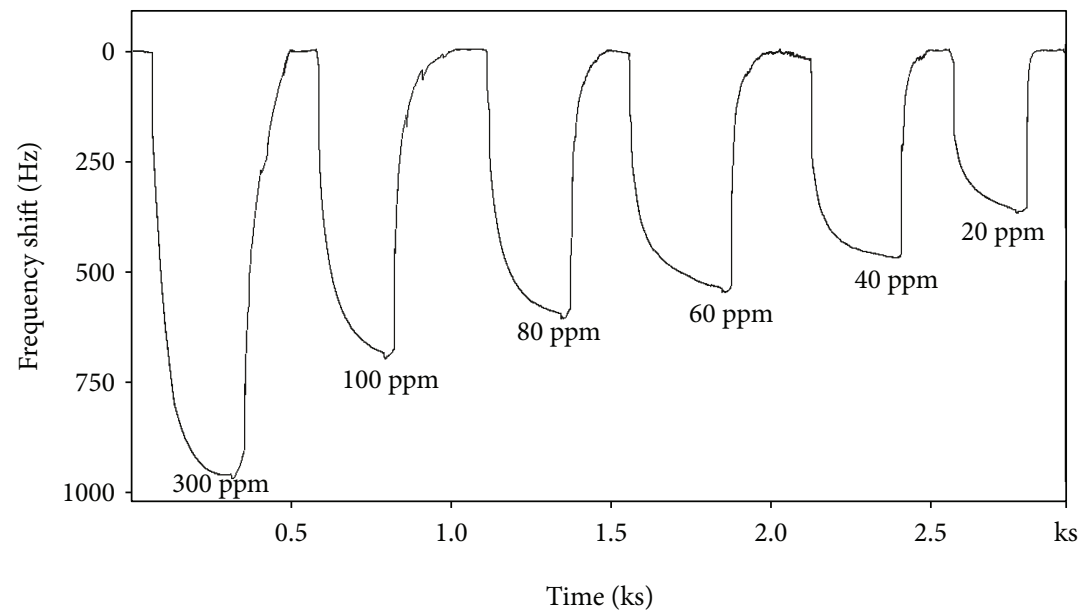

FIGURE 4: Dynamic response of sensor $\mathrm{S} 2$ to $\mathrm{NH}_{3}$ for various concentrations.

gives better results in all cases. For example, the sensitivity of $\mathrm{S} 1$ in the presence of $\mathrm{NH}_{3}$ is 2.00 while for S2 it is 3.33. It is also clear from Table 1 that the LOD of S2 is improved in comparison to that of $\mathrm{S} 1$, as well. The smallest LOD of $9 \mathrm{ppm}$ was registered by sensor $\mathrm{S} 2$ in the presence of $\mathrm{NH}_{3}$.

Considering these results, it can be stated that $\mathrm{Co}_{3} \mathrm{O}_{4}$ shows selectivity for $\mathrm{NH}_{3}$, while $\mathrm{SnO}_{2}$ significantly improves sensitivity of the sensor.
Figure 4 shows the variation of the frequency shift, response, and recovery times of sensor $\mathrm{S} 2$ for $\mathrm{NH}_{3}$, at different concentrations. It can be seen that the sensor has reversibility and that with the decrease of the analyte concentration, the frequency shift decreases. The response and the recovery times were measured between $10 \%$ and $90 \%$ of the maximum signal. The response time was about $100-120 \mathrm{~s}$, and the recovery time was between 
30 and $50 \mathrm{~s}$ for a concentration of NH3 between 40 and $80 \mathrm{ppm}$.

The best results in the presence of $\mathrm{NH}_{3}$ are obtained for sensor S2, which has the highest frequency shift, for all $\mathrm{NH}_{3}$ concentrations. It was possible to detect $\mathrm{NH}_{3}$ for concentrations down to $20 \mathrm{ppm}$ (see the inset of Figure 2), with a LOD of $9 \mathrm{ppm}$. In addition, S2 has good selectivity for $\mathrm{NH}_{3}$, as a comparison between results for VOCs and $\mathrm{NH}_{3}$ shown in Table 1 . Since good selectivity to $\mathrm{NH}_{3}$ also appears in the case of sensor $\mathrm{S} 1$, we can attribute it to the $\mathrm{Co}_{3} \mathrm{O}_{4}$-sensitive layer common to S2 and S1. Therefore, the improved sensitivity and LOD of $\mathrm{S} 2$ can be attributed to the $\mathrm{SnO}_{2}$ layer.

A significant increase in film conductance was observed in [15] when a $\mathrm{Co}_{3} \mathrm{O}_{4}$-sensitive film is exposed to $\mathrm{NH}_{3}$. The authors of [15] therefore concluded that the response of the SAW sensor based on such a film is due both to this shift in film conductance and to a mass effect. The $\mathrm{NH}_{3}$ sensing mechanism based on the shift in film conductance, involved in $\mathrm{Co}_{3} \mathrm{O}_{4}$-based sensors, has been attributed to resistance changes due to surface conductivity modulation by the adsorption and desorption of gas molecules [7].

In the case of our $\mathrm{SnO}_{2} / \mathrm{Co}_{3} \mathrm{O}_{4}$ bilayers, the oxygen species in the surrounding air which are adsorbed on the surface of the porous-sensitive $\mathrm{SnO}_{2}$ layer diffuse to the $\mathrm{Co}_{3} \mathrm{O}_{4}$ surface. At RT, the free electrons are then captured by the adsorbed oxygen species, forming reactive oxygen ion species at the surface, as in equation (1) [25].

$$
\begin{gathered}
\mathrm{O}_{2(\mathrm{~g})} \longrightarrow \mathrm{O}_{2(\mathrm{ad})} \\
\mathrm{O}_{2(\mathrm{ad})}+\mathrm{e}^{-} \longrightarrow \mathrm{O}_{2(\mathrm{ad})}^{-}
\end{gathered}
$$

Thus, at the surface of the $\mathrm{Co}_{3} \mathrm{O}_{4}$ p-type semiconductor, a hole accumulation layer is formed. When $\mathrm{Co}_{3} \mathrm{O}_{4}$ has a porous structure, the accumulation layer is correspondingly formed over a larger surface.

When exposed to $\mathrm{NH}_{3}$, there is a reaction with the highly reactive oxygen ions on the surface of the $\mathrm{Co}_{3} \mathrm{O}_{4}$ and a release of the trapped electrons [25].

$$
\begin{aligned}
\mathrm{NH}_{3(\text { gas })} & \longrightarrow \mathrm{NH}_{3(\text { ads })} \\
4 \mathrm{NH}_{3(\text { ads })}+3 \mathrm{O}_{2}^{-} & \longrightarrow 2 \mathrm{~N}_{2}+6 \mathrm{H}_{2} \mathrm{O}+3 \mathrm{e}^{-}
\end{aligned}
$$

This generates a resistance variation and a variation of the surface conductivity, which in turn leads to a shift in the central frequency $[15,16]$.

In addition, the use of two different types of oxides, p-type $\left(\mathrm{Co}_{3} \mathrm{O}_{4}\right)$ and n-type $\left(\mathrm{SnO}_{2}\right)$, in their interaction area, leads to the formation of heterojunctions. These are active areas that favor the adsorption of oxygen species, thus increasing sensitivity of the sensor [26].

A great influence on the results obtained was that the sensitive films were porous. This type of morphology confers a large contact surface between the sensing material and gas and also favors the diffusion of the gas on its volume [27].

\section{Conclusions}

In conclusion, porous thin films were deposited by PLD onto the quartz substrates of SAW sensors. Sensor S1 was coated with a single layer of $\mathrm{Co}_{3} \mathrm{O}_{4}$, while sensor $\mathrm{S} 2$ had a $\mathrm{SnO}_{2} /-$ $\mathrm{Co}_{3} \mathrm{O}_{4}$ bilayer. Sensors were tested at $\mathrm{RT}$ in the presence of $\mathrm{NH}_{3}$, methanol, and toluene, at various concentrations, at RT. The best responses were obtained for sensor S2, especially in the presence of $\mathrm{NH}_{3}$. The sensitivity of $\mathrm{S} 2$ in the presence of $\mathrm{NH}_{3}$ was $3.33 \mathrm{~Hz} / \mathrm{ppm}$, with a LOD of $9 \mathrm{ppm}$. The response and the recovery times for $\mathrm{S} 2$ to $\mathrm{NH} 3$ were 100-120 s and 30-50 s, respectively. Thus, it could be stated that at $\mathrm{RT}, \mathrm{Co}_{3} \mathrm{O}_{4}$ is selective for $\mathrm{NH}_{3}$, while $\mathrm{SnO}_{2}$ has the ability to improve sensitivity of the sensor.

\section{Data Availability}

No data were used to support this study.

\section{Conflicts of Interest}

The authors declare that there is no conflict of interest regarding the publication of this paper.

\section{Acknowledgments}

This work was supported by a grant of the Romanian Ministry of Research and Innovation, CCCDI-UEFISCDI (project number PN-III-P1-1.2-PCCDI-2017-0172/15PCCDI and project LAPLAS VI, 16N /08.02.2019).

\section{References}

[1] A. Valera-Medina, H. Xiao, M. Owen-Jones, W. I. F. David, and P. J. Bowen, "Ammonia for power," Progress in Energy and Combustion Science, vol. 69, pp. 63-102, 2018.

[2] S. Gaskin, D. Pisaniello, J. W. Edwards et al., "Application of skin contamination studies of ammonia gas for management of hazardous material incidents," Journal of Hazardous Materials, vol. 252-253, pp. 338-346, 2013.

[3] C. C. Ojiodu, T. Kuteyi, and O. E. Gbenga, "Presence of volatile organic compound (VOCs) in the atmosphere of Ilupeju industrial area, Lagos state, Southwestern - Nigeria," Scientific Journal of Pure and Applied Sciences, vol. 2, pp. 369-378, 2013.

[4] T. E. Burghardt and A. Pashkevich, "Emissions of volatile organic compounds from road marking paints," Atmospheric Environment, vol. 193, pp. 153-157, 2018.

[5] N. T. Garavand, S. M. Mahdavi, and A. I. zad, "Pt and Pd as catalyst deposited by hydrogen reduction of metal salts on $\mathrm{WO}_{3}$ films for gasochromic application," Applied Surface Science, vol. 273, pp. 261-267, 2013.

[6] J. Huotari, V. Kekkonen, T. Haapalainen et al., "Pulsed laser deposition of metal oxide nanostructures for highly sensitive gas sensor applications," Sensors and Actuators B: Chemical, vol. 236, pp. 978-987, 2016.

[7] J. Deng, R. Zhang, L. Wang, Z. Lou, and T. Zhang, "Enhanced sensing performance of the $\mathrm{Co}_{3} \mathrm{O}_{4}$ hierarchical nanorods to $\mathrm{NH}_{3}$ gas," Sensors and Actuators B: Chemical, vol. 209, pp. 449-455, 2015. 
[8] M. Cole, I. Spulber, and J. W. Gardner, "Surface acoustic wave electronic tongue for robust analysis of sensory components," Sensors and Actuators B: Chemical, vol. 207, pp. 1147-1153, 2015.

[9] V. B. Raj, A. T. Nimal, Y. Parmar, M. U. Sharma, K. Sreenivas, and V. Gupta, "Cross-sensitivity and selectivity studies on $\mathrm{ZnO}$ surface acoustic wave ammonia sensor," Sensors and Actuators B: Chemical, vol. 147, no. 2, pp. 517-524, 2010.

[10] C. Chen, M. Yang, J. Chen, and C. Liang, "The viscoelastic contribution to polymer-coated SAW sensor for TNT vapor detection," Optik, vol. 127, no. 7, pp. 3638-3642, 2016.

[11] C. Viespe and D. Miu, "Surface Acoustic Wave Sensor with $\mathrm{Pd} / \mathrm{ZnO}$ bilayer structure for room temperature hydrogen detection," Sensors, vol. 17, p. 1529, 2017.

[12] L. Yang, C. Yin, Z. Zhang, J. Zhou, and H. Xu, "The investigation of hydrogen gas sensing properties of SAW gas sensor based on palladium surface modified $\mathrm{SnO}_{2}$ thin film," Materials Science in Semiconductor Processing, vol. 60, pp. 16-28, 2017.

[13] V. Dinca, C. Viespe, S. Brajnicov et al., "MAPLE assembled acetylcholinesterase-polyethylenimine hybrid and multilayered interfaces for toxic gases detection," Sensors, vol. 18, no. 12 , p. $4265,2018$.

[14] B. Wu, L. Wong, and $\mathrm{H}$. Wu, "Templated synthesis of 3D hierarchical porous $\mathrm{Co}_{3} \mathrm{O}_{4}$ materials and their $\mathrm{NH}_{3}$ sensor at room temperature," Microporous and Mesoporous Materials, vol. 225, pp. 154-163, 2016.

[15] Y.-L. Tang, Z.-J. Li, J.-Y. Ma et al., "Highly sensitive roomtemperature surface acoustic wave (SAW) ammonia sensors based on $\mathrm{Co}_{3} \mathrm{O}_{4} / \mathrm{SiO}_{2}$ composite films," Journal of Hazardous Materials, vol. 280, pp. 127-133, 2014.

[16] A. J. Ricco, S. J. Martin, and T. E. Zipperian, "Surface acoustic wave gas sensor based on film conductivity changes," Sensors and Actuators, vol. 8, pp. 319-333, 1985.

[17] W. Jakubik, P. Powroźnik, J. Wrotniak, and M. Krzywiecki, "Theoretical analysis of acoustoelectrical sensitivity in SAW gas sensors with single and bi-layer structures," Sensors and Actuators B: Chemical, vol. 236, pp. 1069-1074, 2016.

[18] A. M. Al-Enizi, M. Naushad, A. H. Al-Muhtaseb et al., "Synthesis and characterization of highly selective and sensitive $\mathrm{Sn} / \mathrm{SnO}_{2} / \mathrm{N}$-doped carbon nanocomposite ( $\left.\mathrm{Sn} / \mathrm{SnO}_{2} @ \mathrm{NGC}\right)$ for sensing toxic $\mathrm{NH}_{3}$ gas," Chemical Engineering Journal, vol. 345 , pp. 58-66, 2018.

[19] M. Hijazi, V. Stambouli, M. Rieu, G. Tournier, C. Pijolat, and J.-P. Viricelle, "Sensitive and selective ammonia gas sensor based on molecularly modified $\mathrm{SnO}_{2}$," Proceedings, vol. 1, p. 399, 2017.

[20] W. Wei, W. Li, and L. Wang, "High-selective sensitive $\mathrm{NH}_{3}$ gas sensor: A density functional theory study," Sensors and Actuators B: Chemical, vol. 263, pp. 502-507, 2018.

[21] P. Płóciennik, A. Zawadzka, R. Frankowski, and A. Korcala, "Selected methods of thin films deposition and their applications," in IEEE, 2016.

[22] C. Viespe, "Surface acoustic wave sensors based on nanoporous films for hydrogen detection," Key Engineering Materials, vol. 605, pp. 331-334, 2014.

[23] Y. Li, A.-S. Xiao, B. Zou, H.-X. Zhang, K.-L. Yan, and Y. Lin, "Advances of metal-organic frameworks for gas sensing," Polyhedron, vol. 154, pp. 83-97, 2018.
[24] C. Viespe and A. Marcu, "Surface acoustic wave sensors for hydrogen and deuterium detection," Sensors, vol. 17, p. 1417, 2017.

[25] Z. Li, Z. Lin, N. Wang et al., "High precision $\mathrm{NH}_{3}$ sensing using network nano-sheet $\mathrm{Co}_{3} \mathrm{O}_{4}$ arrays based sensor at room temperature," Sensors and Actuators B: Chemical, vol. 235, pp. 222-231, 2016.

[26] S. Sharma, A. Kumar, N. Singh, and D. Kaur, "Excellent room temperature ammonia gas sensing properties of n-MoS2/p$\mathrm{CuO}$ heterojunction nanoworms," Sensors and Actuators B: Chemical, vol. 275, pp. 499-507, 2018.

[27] J. M. Xu and J. P. Cheng, "The advances of $\mathrm{Co}_{3} \mathrm{O}_{4}$ as gas sensing materials: a review," Journal of Alloys and Compounds, vol. 686, pp. 753-768, 2016. 


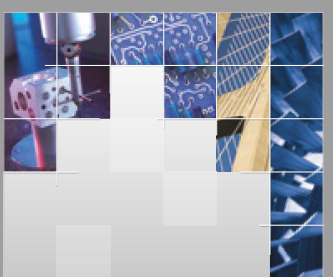

\section{Enfincering}
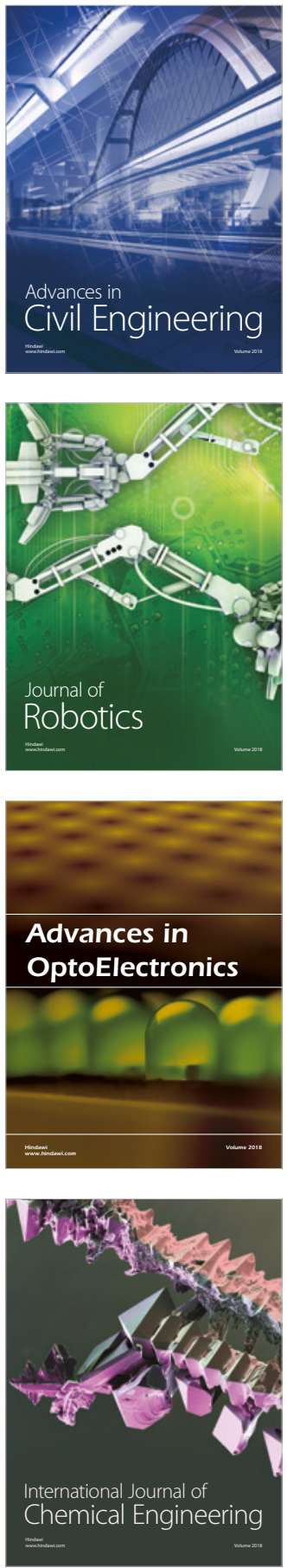

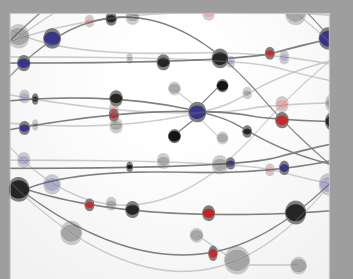

\section{Rotating \\ Machinery}

The Scientific World Journal

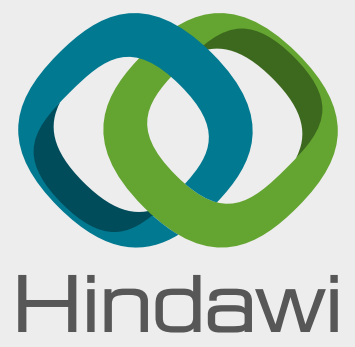

Submit your manuscripts at

www.hindawi.com
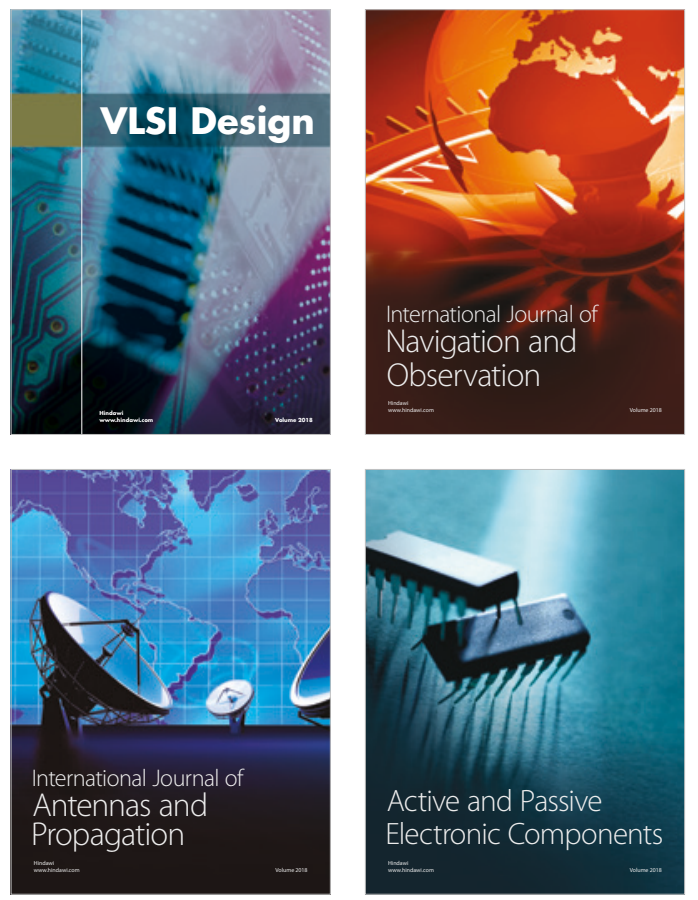
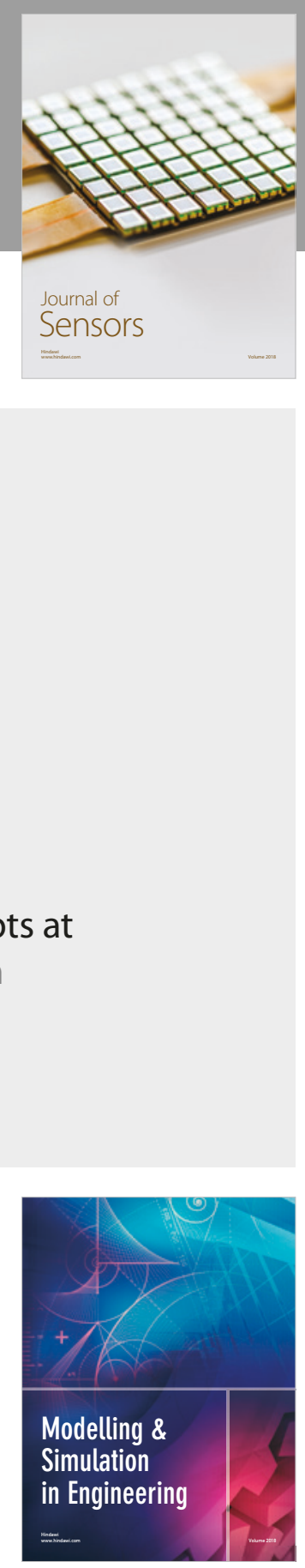

\section{Advances \\ Multimedia}
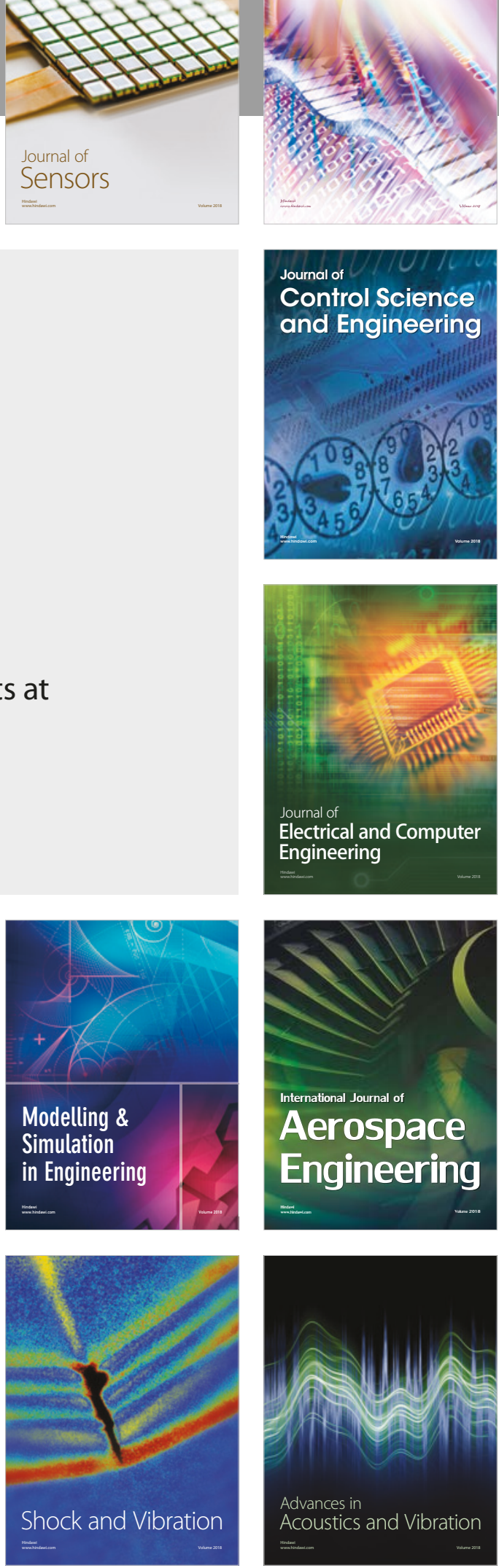